\title{
Review
}

\section{Nutritional Characteristics and Health Benefits of Diacylglycerol in Foods}

\author{
Noboru MATSUO \\ Kao Corporation, Health Care Products Research Laboratories, Tokyo, Japan
}

Received February 20, 2004; Accepted April 27, 2004

In this review nutritional characteristics and the health benefits of dietary diacylglycerol are summarized. The global obesity epidemic and our knowledge of its relation to human health have increased research on dietary fat control. Among several approaches, we have focused on the structure of acylglycerols and have studied nutritional functions of diacylglycerol oil in comparison with conventional triacylglycerol oil with the same fatty acid composition. A cooking oil product containing $80 \%(w / w)$ or more diacylglycerol has been used in Japan since 1999 as a "Food for Specified Health Use" approved by the Ministry of Health, Labour and Welfare. The approved claims are: (i) Less increase in postprandial triacylglycerol concentrations in the blood and (ii) Less likelihood of being stored as body fat. These effects are probably the result of the unique metabolic characteristics of diacylglycerol because its bioavailability is practically the same as that of triacylglycerol oil. Although studies of its digestion, absorption and metabolic processes are yet to be completed, the ingestion of diacylglycerol oil has been shown to be beneficial in reducing risk factors for life-style related diseases.

Keywords: diacylglycerol, triacylglycerol, body weight, body fat, lifestyle-related disease, health benefit, risk factor

Fats and oils are not only essential nutrients but also contribute to the flavor and aroma of foods. However, an excessive intake of fat can result in obesity. The prevalence of obesity has dramatically increased throughout the world over the last decades (for example, see Mokdad et al., 2003). Many investigators and surveys have noted the importance of preventing the accumulation of body fat that is associated with certain lifestyle related diseases. Clinical studies suggest that weight loss in the range of $5-10 \%$ of initial weight can lead to a significant reduction in obesity-related disorders such as heart disease, diabetes mellitus, and hypertension. Although energy restriction and limiting total and saturated fat intake may be the primary measures for the treatment of obesity, these are difficult to achieve. As a result, numerous studies on dietary fats that influence the accumulation of body fat have been conducted.

Dietary diacylglycerol (DAG) is a natural component of various edible oils and has been used in foods as an emulsifier. The nutritional characteristics of dietary DAG have been examined in comparison to triacylglycerol (TAG) and the findings in these studies show that DAG, particularly in the 1,3-isoform, has metabolic characteristics that are distinct from TAG which may produce beneficial effects with regard to the prevention and management of postprandial lipemia and obesity. A cooking oil product containing $80 \%(\mathrm{w} / \mathrm{w})$ or more DAG has been on the market in Japan since 1999 as a "Food for Specified Health Use" as approved by the Ministry of Health, Labour and Welfare. In this article, after briefly reviewing the strategies for the treatment of obesity, the current state of studies on the nutritional benefits of dietary DAG observed in the clinical trials and mechanistic studies using animal models are outlined.

E-mail: noboru.matsuo2@kao.co.jp
Research directed at agents for the treatment of obesity

Changes in dietary habits and exercise are the most popular recommendations for preventing obesity and the metabolic syndrome. However, fats and oils that are good for health in addition to taste are the target of investigators as well. The goal of such studies is the treatment of obesity that resides upstream of various metabolic syndromes such as diabetes, hypertension, hyperlipidemia, and arteriosclerosis (Matsuzawa et al., 1995; Rimm et al., 1995; Zimmet et al., 2001). Clinical trials have shown the effectiveness of diet intervention (Levy \& Heaton, 1993; National Institute of Health, National Heart, Lung, and Blood Institute, Obesity Education înitiative, 1998), fat substitutes (Bray et al., 2002) and medical drugs (Davidson et al., 1999; Wirth \& Krause, 2001) on weight loss in overweight or obese subjects. Through these agents, approximately 5-10\% weight reduction during a treatment period can be readily achieved.

During the last two decades, fat-substitutes such as modified starch, cellulose, protein, pectin, dextrose have been developed in attempts to produce a material with the same texture as fat (Wylie-Rosett, 2002). On the other hand, Salatrim and Caprenin (Wylie-Rosett, 2002), low energy oils that contain $5 \mathrm{kcal} / \mathrm{g}$ compared to conventional edible oils $(9 \mathrm{kcal} / \mathrm{g})$ have been developed. These structural fats contain short or medium chain fatty acids, which partially replace the original long chain fatty acids of TAG, and are produced by inter-esterification techniques. Olestra is another type of synthetic fat substitute consisting of fatty acid esters of sucrose (Wylie-Rosett, 2002; Stubbs, 2001). The properties of olestra are similar to those of naturally occurring fat, but it is indigestible and passes through the digestive tract, thus providing zero calories. The FDA approved olestra in 1996 for use in potato chips, crackers, torti- 
lla chips and other savory snacks in the U.S.

Medium chain triglycerides (MCT) containing mainly $\mathrm{C} 8$ and $\mathrm{C} 10$ fatty acids have recently been reported to reduce body fat in humans (Tsuji et al., 2001). This and other available data describe the effects of MCT on energy expenditure and satiety and determine their potential efficacy as agents in the treatment of human obesity (St-Onge \& Jones, 2002). In relation to MCT, TAG, which contains both medium- and long-acyl chains in a molecule has been shown to reduce the accumulation of body fat in healthy humans (Kasai et al., 2003).

It has recently been reported that conjugated linoneic acid (CLA) consumption improves lipid metabolism, obesity and cancer (Brown \& McIntosh, 2003). It has been demonstrated that CLA isomers prevent the development of obesity in certain rodent and pig models. This was attributed mainly to the presence of trans-10, cis-12 CLA. However, the ability of CLA to modulate obesity and its safety in humans is currently a matter of debate (Larsen et al., 2003).

The health benefits of fish oil, which is rich in the $\omega-3$ polyunsaturated fatty acids ( $\omega 3$-PUFA) such as docosahexanoic acid (DHA) and eicosapentaenoic acid (EPA), have been reported (Vanschoonbeek et al., 2003; de Lorgeril \& Salen, 2003). These include a decreased lipid concentration in the blood and a reduction in body weight and body fat weight (Ikemoto et al., 1996). w3-PUFA consumption has also been shown to reduce platelet activation, lower (vitamin $\mathrm{K}$-dependent) coagulation factors and/or decrease vascular tone, which may contribute to a reduction in arterial disease (Vanschoonbeek et al., 2003; de Lorgeril \& Salen, 2003) and blood pressure (Weisinger et al., 2001). $\alpha$-Linolenic acid (ALA), another type of $\omega 3$-PUFA, is the major component of perilla oil and flaxseed oil with a content approximately $60 \mathrm{wt} \%$ or greater. Emerging evidence suggests that diets containing ALA are associated with reductions in total deaths and sudden cardiac death (de Lorgeril \& Salen, 2003; Sinclair et al., 2002). There is a continuing debate regarding whether ALA has unique actions in relation to the cardiovascular system (Sinclair et al., 2002). Dietary $\omega$-3-PUFA are also reported to reduce the activities of enzymes involved in fatty acid and TAG synthesis, and to stimulate fatty acid oxidation and thermogenesis in the liver, skeletal muscle, and adipose tissue (Jump \& Clarke 1999; Ide et al., 2000; Kabir \& Ide, 1996).

Thus, certain dietary oils, possibly due to their fatty acid constituents, show beneficial effects on lipid metabolism in various organs and thereby on obesity and diabetes. In contrast to these studies that have been mainly focused on the nutrition of fatty acids in the TAG molecule, the focus of the study on dietary DAG described below is on glyceride structure. Diacylglycerol has two main health benefits: the suppression of postprandial serum TAG elevation as a short-term effect and the suppression of body fat accumulation as a long-term effect.

\section{Structure of DAG and its occurrence in natural oils and fats}

The largest constituent of edible oil is TAG, but it generally contains up to about $10 \%(\mathrm{w} / \mathrm{w}) \mathrm{DAG}$, with the relative content depending on the origin of the oil. For example, olive oil contains 5.5\% DAG and cottonseed oil contains 9.5\% DAG (Abdel-Nabey et al., 1992; D'alonzo et al., 1982). These values may, of course, vary depending on a number of conditions such

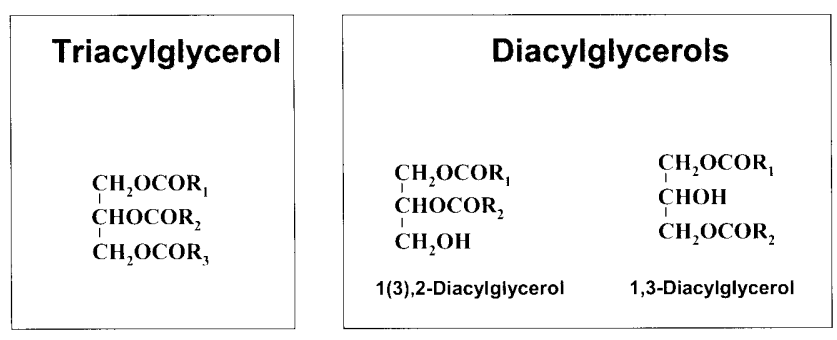

Fig. 1. Structure of diacylglycerol and triacylglycerol.

as the variety of the oil plant, storage conditions, etc. DAG can exist in two isoforms, 1,2 (or 2,3)-diacyl-sn-glycerol (1,2DAG) and 1,3-diacyl-sn-glycerol (1,3-DAG). Figure 1 illustrates the structures of DAG in comparison with TAG. DAG is a metabolic intermediate, produced after the ingestion of TAG.; this metabolic intermediate is in the 1,2-DAG isoform. On the other hand, the majority of the DAG in edible oils has been converted to 1,3-DAG via acyl group migration during the manufacturing process under elevated temperatures (Crossley et al., 1959; Kodali et al., 1990) and during storage. Acylmigration is an equilibrium reaction. The amount of 1,3-isoform present at equilibrium is dependent on the fatty acids in the DAG molecule (Crossley et al., 1959). For example, at equilibrium, the amount of 1,3-dipalmitoyl-sn-glycerol is $56 \%$ (w/w) (Kodali et al., 1990). Approximately 70\% of DAG with common fatty acids is in the 1,3-isoform.

An oil rich in 1,3-DAG can be prepared by esterifying glycerol with fatty acids from natural vegetable oils as described by Watanabe et al. (2003) using the reverse reaction of an immobilized lipase. Most of the TAG oil used as a control oil in the study was prepared by blending rapeseed oil, soybean oil and safflower oil such that the fatty acid composition matches that of DAG oil.

\section{Energy value and absorption coefficient of DAG}

The combustion heat of DAG oil containing 87\% DAG was $38.9 \mathrm{~kJ} / \mathrm{g}(9.29 \mathrm{kcal} / \mathrm{g})$ and that of the TAG oil with the same fatty acid composition was $39.6 \mathrm{~kJ} / \mathrm{g}(9.46 \mathrm{kcal} / \mathrm{g}$ ) (Taguchi et al., 2001). This difference in energy value between DAG oil and TAG oil is likely negligible in the practical consumption of oils. Furthermore, the apparent absorption coefficients of DAG and TAG oils determined in rats were similar $(96.3 \%$ ) (Taguchi et al., 2001). These results indicate that the physiological differences between DAG and TAG observed in humans and animals described in this article are likely to be caused by differences in metabolic fate after absorption by gastrointestinal epithelial cells.

\section{Metabolic characteristics of DAG as compared to TAG}

The digestion and absorption of DAG was first investigated in an experiment involving time-course changes in lipid composition after the perfusion of triolein and diolein (1,2-:1,3diolein=3:7) in the intestinal tract of rats (Watanabe et al., 1997). More recently, Kondo et al. (2003) investigated the digestion products after TAG or DAG was intraduodenally infused in the form of emulsion. Results showed that TAG was converted to 1,2-DAG, 2-MAG and FFA, whereas 1,3-DAG 


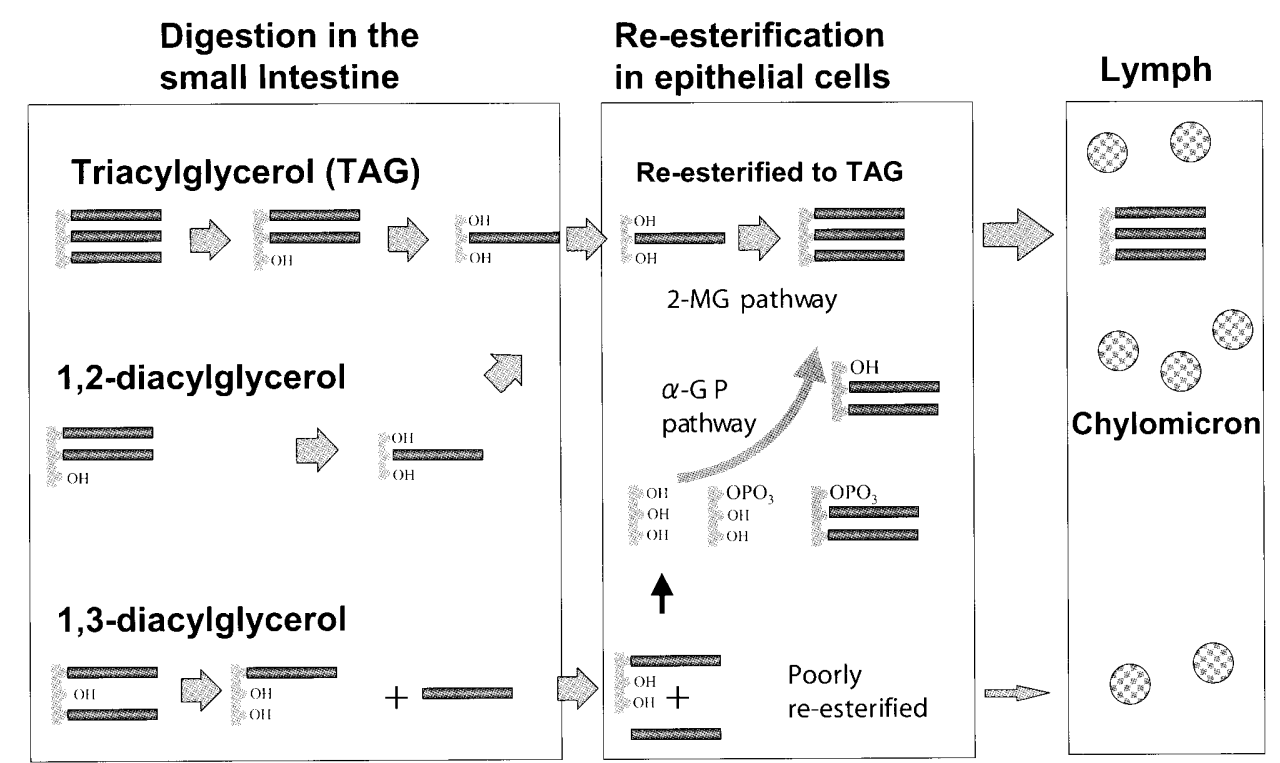

Fig. 2. Metabolic characteristics of diacylglycerol (DAG) in comparison with triacylglycerol (TAG). 2-MG, 2-monoacylglycerol: $\alpha$-GP, $\alpha$-glycerophosphate: horizontal rectangulars, fatty acids; vertical bars, glycerol structure; hatched circles, chylomicron particles.

was digested to 1(3)-MAG, and FFA. Thus, the production of 1(3)-MAG instead of 2-MAG is unique to DAG digestion. The TAG resynthesis pathway in small intestinal epithelial cells includes the 2-MAG pathway and the $\alpha$-glycerophosphate $(\alpha-$ GP) pathway (Fig. 2), with the former being predominant during the digestion and absorption of ordinary fat. While 2-MAG is easily utilized in the 2-MAG pathway, the reactivity of 1(3)MAG is lower (Lehner et al., 1993). Free glycerol is a substrate for the $\alpha$-glycerophosphate pathway, but its contribution to the resynthesis of TAG is small. The incorporation of ${ }^{14} \mathrm{C}$-labelled linoleic acid into TAG was significantly retarded in the intestinal mucosa of rats in which a DAG oil emulsion, as compared to a TAG oil emulsion, had been infused (Kondo et al., 2003). Murata et al. reported that the rate of release of resynthesized TAG into intestinal lymph chylomicrons was lower after the administration of a DAG emulsion compared to that of a TAG emulsion (Murata et al., 1994). A slower lymphatic secretion of ${ }^{14} \mathrm{C}$-labeled triolein after intra-gastric infusion of ${ }^{14} \mathrm{C}-1,3-$ diolein has also been demonstrated in rats (Yanagita \& Ikeda, 2003). This may be the result of a decreased rate of reesterification of fatty acids after DAG ingestion. Figure 2 illustrates the metabolic characteristics of DAG as compared with TAG.

In terms of beneficial effects other than nutritional effects, we investigated the stomach emptying time of ingested scrambled eggs cooked with DAG oil. The subjects ingested scrambled eggs cooked with either DAG or TAG oil or no oil. The stomach emptying time was monitored using technetium labeled albumin as a probe in a scintigram. The half emptying time of scrambled eggs cooked with DAG oil was shorter than that cooked with control TAG oil (Yasunaga et al., 2000). In the initial phase of our nutritional study of DAG, we hypothesized that DAG might be more easily digested than TAG. This was based on findings that infants, who have an immature digestive system, secrete a specific lipase in their mouth when consuming TAG and convert it to DAG. A shorter stomach emptying time of DAG is consistent with this hypothesis.

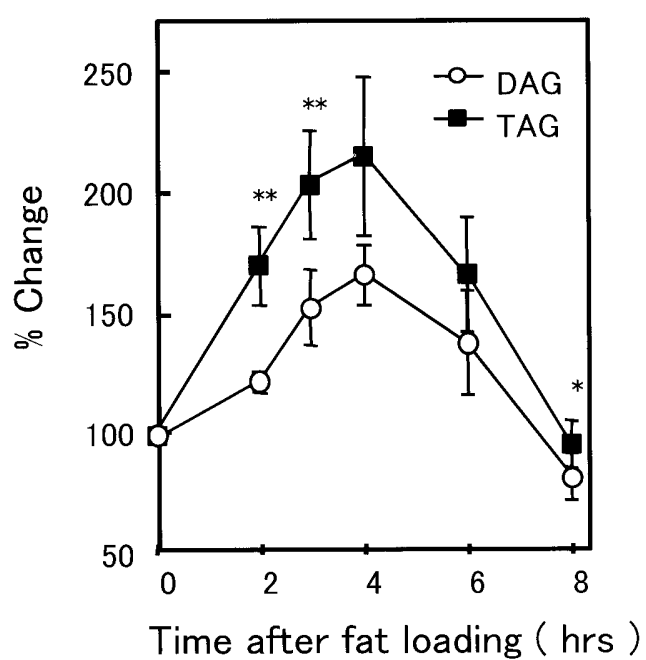

Fig. 3. Postprandial increase of serum triacylglycerol after ingestion of diacylglycerol emulsion and triacylglycerol emulsion in humans. Percent change from the initial value \pm SEM. Significant difference between treatment: $* p<0.05, * * k<0.01$

\section{Less postprandial lipemia in humans after the ingestion of DAG}

Serum TAG levels increase after the ingestion of a meal containing fat and then decrease as TAG, in the form of chylomicrons, is cleared from the circulation by enzymatic hydrolysis (Goldberg, 1996) and receptor-mediated uptake (Eriksson et al., 1991). Because of the slow clearance of chylomicron TAG, humans typically spend most of the time in a postprandial hypertriglyceridemic state. Since chylomicrons and their cholesterol-rich remnants are implicated in atherogenesis (Zilversmit, 1979; Patsch, 1987; Gianturco \& Bradley, 1991; Patsch et al., 1992; Cohn, 1998), the possibility exists that the risk of coronary artery disease and atherosclerosis could be reduced by avoiding excess TAG concentration in the circulation during the postprandial phase. Factors that influence the magnitude of postprandial lipemia have been investigated in 
A

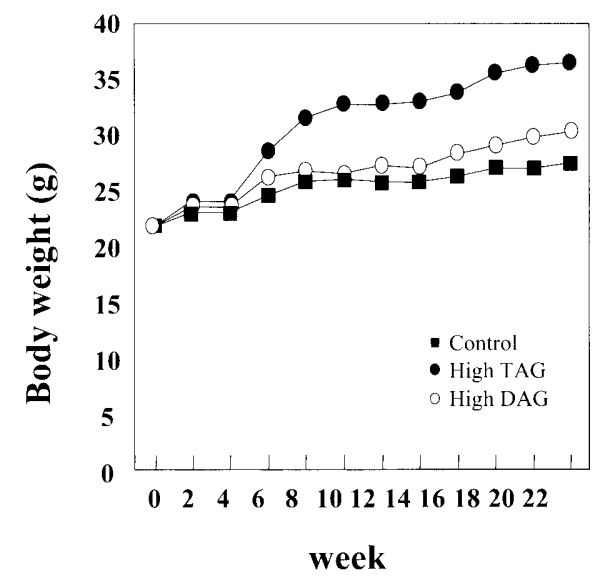

B

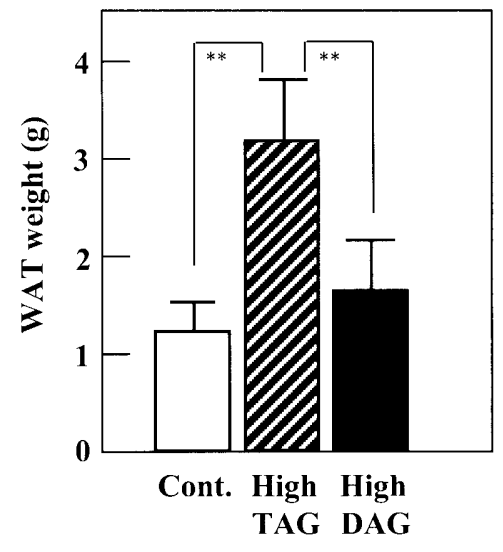

Fig. 4. Effect of diacylglycerol ingestion on body weight (panel A) and total vesceral fat (panel B) in C57BL/6J mice. Panel $\mathrm{A}$, body weight changes during the study period; Panel B, intra-abdominal white adipose tissue (WAT) weight. Sum of epididymal, mesenteric, retroperitoneal and perirenal WAT at the end of the study $(5$ months) are shown. Mean \pm SD. Cont, low fat control diet; high DAG, high fat DAG diet; high TAG, high fat TAG diet. humans (Cohen et al., 1988; Cohn et al., 1988; Jeppesen et al., 1995; Dubois et al., 1998).

Human studies have been conducted to compare the postprandial states of lipids in serum and in remnant-like lipoprotein particles (RLP). Taguchi et al. showed that TAG concentrations in the chylomicron fraction were markedly lower after the ingestion of DAG than after that of TAG (Taguchi et al., 2000). The lower serum TAG levels after DAG ingestion may be the result of the slower rate of chylomicron formation after DAG ingestion compared with that of ingested TAG. With respect to risk factors, DAG has been shown to weaken the postprandial increase in RLP-TAG, which is a more potent risk factor of cardiovascular diseases than whole serum TAG concentrations (Tada et al., 2001).

Figure 3 shows changes in serum TAG concentrations after the ingestion of lipid emulsion by healthy men (Tada et al., 2001). The two test oils had the same fatty acid composition. The lower serum TAG levels after DAG ingestion may be the result of a slower rate of chylomicron formation after DAG ingestion compared with that of TAG ingestion as discussed in the previous section.

In addition to postprandial studies, serum TAG in the fasting state has been studied in diabetic patients with hypertriglyceridemia. Type 2 diabetes, abnormal lipid metabolism, hypertension, hyperuricemia/gout, arteriosclerotic diseases and fatty liver are known complications of obesity. The impact of diet therapy in a treatment of these life-style related diseases is widely recognized. A randomized, single-blind, controlled parallel trial was conducted involving type 2 diabetic patients (Yamamoto et al., 2001). In this study, the influence of DAG oil consumption by substituting DAG cooking oil for ordinary TAG oil over a three month period on blood lipids was examined in 16 type 2 diabetic patients. The serum TAG levels of these patients were consistently increased despite continuous nutritional counseling at an outpatient clinic over a one year period. The primary outcome of this study was a reduction in serum TAG levels in the DAG group (from $2.51 \pm 0.75$ to $1.52 \pm 0.28 \mathrm{mmol} / l, p<0.01)$ after a three-month treatment. These effects were not associated with an increase in ketone bodies in the serum.

\section{Anti-obesity effects of DAG in animal studies}

Experiments were conducted to investigate how DAG consumption affects body weight and fat mass over a long period of time. The efficacy of DAG oil in reducing body weight and fat mass were assessed in both animals and humans.

Animal models have been used extensively to investigate the effects of DAG and to elucidate the mechanism of its action. When C57BL/6J mice (obesity- and diabetes-prone model mice) were fed a high fat $(30 \%, \mathrm{w} / \mathrm{w})$ and sucrose $(13 \%, \mathrm{w} / \mathrm{w})$ diet for five months, body weight and body fat (white adipose tissue, WAT) mass increased, compared to a control low fat diet. Insulin and leptin (a peptide product of the $\mathrm{OB}$ gene which is associated with obesity in mice as well as in humans) concentrations also increased in these mice. Substituting DAG for TAG prevented the increases in body weight and fat accumulation associated with the high fat and sucrose diet (Fig. 4) (Murase et al., 2001). Increases in insulin and leptin concentrations were also prevented by substituting TAG with DAG. Mice consuming a DAG diet were able to maintain smaller fat stores suggesting that DAG consumption produced an increase in energy expenditure. This must be proven experimentally. No differences in total energy or fecal fat were noted between the DAG and TAG oil treatments.

Although the mechanism for the suppression of body fat accumulation by a DAG diet is yet to be elucidated, it may be due, at least in part, to an increased beta-oxidation in the liver induced by DAG. When food containing 10\% DAG was given to rats for 2-3 weeks, the enzyme activity relative to fatty acid synthesis in the liver was decreased and that for beta-oxidation of fatty acids was increased (Murata et al., 1997). In another experiment with high fat induced obesity model mice (C57BL/ $6 \mathrm{~J}$ ), high DAG diet (for 5 months), as compared to a high TAG diet, increased hepatic acyl-coenzyme $A$ oxidase activity and acyl-coenzyme A synthase mRNA, suggesting a higher capacity for hepatic lipid oxidation (Murase et al., 2001). Using the same animal model, Murase and his colleagues showed that, within the first 10 days (before the onset of obesity), DAG consumption stimulated both beta-oxidation and lipid metabolismrelated gene expression, including acyl-CoA oxidase, mediumchain acyl-CoA dehydrogenase and uncoupling protein- 2 in the small intestine but not in the liver, skeletal muscle nor brown 
Table 1. Changes of anthropometric values and body composition of the subjects."

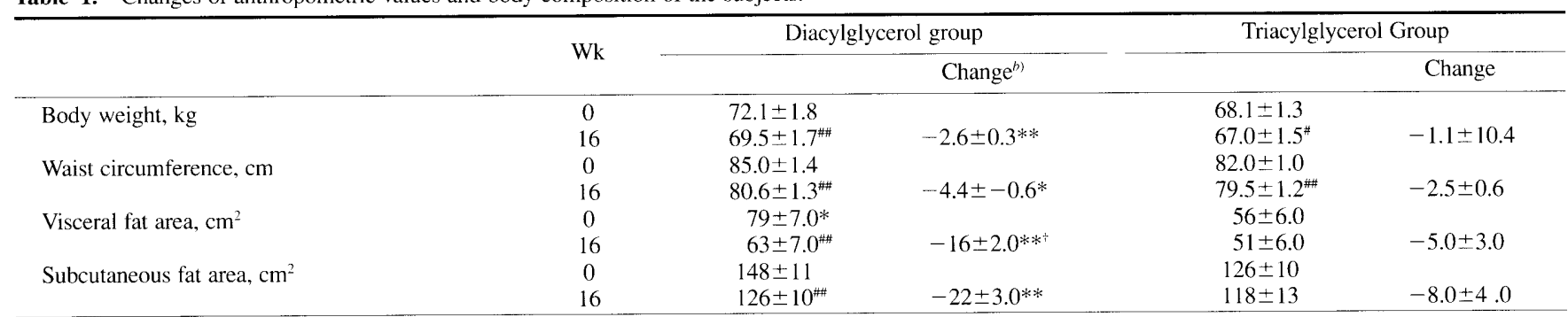

${ }^{a)}$ Values are mean \pm SEM $(n=19),{ }^{b} 16 \mathrm{wk}$ value minus $0 \mathrm{wk}$ value. Significantly different from the initial value by Student's $t$-test: ${ }^{\#} p<0.05$, ${ }^{\# k} p<0.01$. Significantly different from triacylglycerol diet group by Student's $t$-test for paired value: ${ }^{*} p<0.05$, ${ }^{* *} p<0.01$. Significantly different from triacylglycerol diet group by analysis of covariance: ${ }^{\dagger} p<0.05$.

A

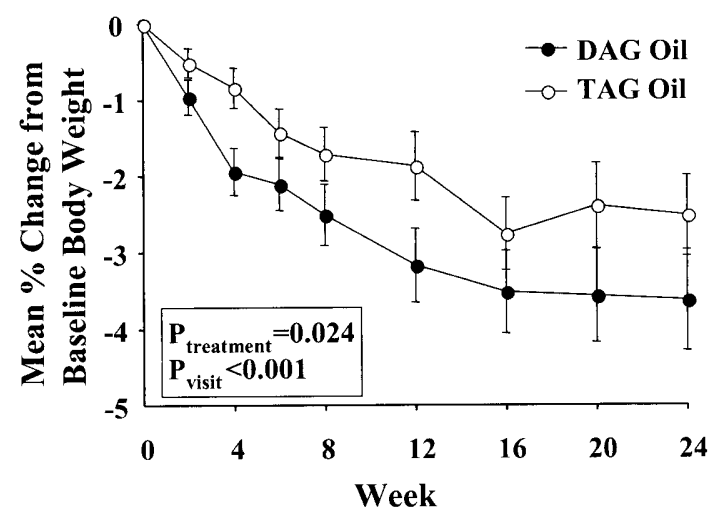

B

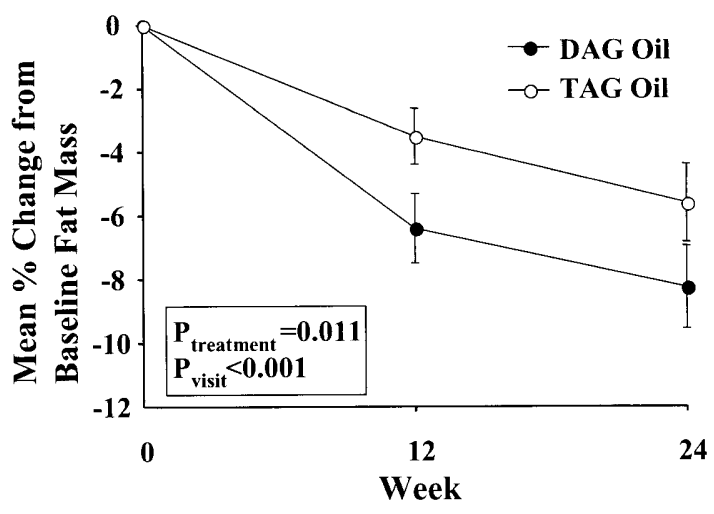

Fig. 5. Effect of diacylglycerol consumption on body weight (panel A) and fat mass (panel B) in obese or overweight Americans. Panel A, percent changes in body weight from baseline to weeks $2,4,6,8,12,16,20$, and 24 among subjects in the intent-to-treat sample assigned to diacylglycerol (DAG) oil ( $n=65$ ) or triacylglycerol (TAG) oil $(n=66)$ treatment groups. Body weights at baseline were $98.0 \pm 1.6 \mathrm{~kg}$ and $97.6 \pm 1.8 \mathrm{~kg}$, for the DAG and TAG groups, respectively; Panel B, percent changes from baseline to week 12 and week 24 in fat mass among subjects in the intent-to-treat sample assigned to diacylglycerol (DAG) oil ( $n=49$ at week 12 and $n=50$ at week 24) or triacylglycerol (TAG) oil ( $n=45$ at week 12 and $n=46$ at week 24$)$. Fat mass at baseline was $35.4 \pm 0.9 \mathrm{~kg}$ and $34.7 \pm 0.9 \mathrm{~kg}$, for the DAG and TAG groups, respectively. For both panels, data are mean \pm SEM and $p$-values are by repeated measures ANOVA.

adipose tissue. This suggested the predominant contribution of intestinal lipid metabolism to the effects of DAG (Murase et al., 2002).

\section{Repeated DAG vs. TAG consumption reduces body fat in humans}

Human studies were conducted both in Japan and the United States to observe the chronic effect of DAG consumption. Nagao et al. (2000) conducted a comparative study of DAG oil and TAG oil in 38 healthy Japanese men. Ten grams out of $50 \mathrm{~g}$ of fat in the daily diet were replaced with the test oil for a period of 16 weeks in a double-blind parallel study. As shown in Table 1, significant decreases were observed in the DAG group compared with the TAG group in body weight, visceral fat, subcutaneous fat and waist circumference. Abdominal fat was evaluated by the area of computed tomography (CT) scan cross-section images.

This Japanese study was expanded using male and female subjects who were categorized as either obese or overweight. The Chicago Center for Clinical Research (Chicago, IL) conducted a double-blind parallel study in which 131 overweight or obese men and women ingested DAG and TAG diets for 24 weeks (Maki et al., 2002). In this study, 15\% of the energy was taken as the test oil under mild hypo-calorie conditions estab- lished by subtracting $500-800 \mathrm{kcal}$ from the energy requirement calculated based on body weight, sex, activity level and age. The food products included muffins, crackers, instant soup mix, sugar cookies and granola bars. On the basis of energyrequirement calculations, the amount of test oil corresponded to 16 to $45 \mathrm{~g} / \mathrm{d}$. The decreases in body weight and body fat were significantly greater in the DAG group than in the TAG group (Fig. 5).

\section{Efficacy of DAG oil incorporated into ordinary meals}

The human studies described above were conducted using either fat emulsions as an experimental food or DAG oil products in strictly controlled diet intake. Therefore, it would be of interest to investigate changes in TAG levels in the serum or body weight after the ingestion of DAG or TAG that had been incorporated into ordinary meals.

The postprandial response of DAG vs. TAG ingestion was investigated using a mayonnaise type solidified dressing prepared from DAG oil (Takase et al., 2003) or a typical breakfast in which a mayonnaise type DAG (10 g DAG oil/60 kg) had been incorporated (Tomonobu et al., 2003). These studies were double blind placebo controlled cross-over studies in which healthy volunteers had been recruited (average BMI: $25 \mathrm{~kg} / \mathrm{m}^{2}$ ). The control was regular mayonnaise prepared with TAG with a 
fatty acid composition similar to DAG.

Changes in serum TAG levels from the initial values were significantly low in the DAG ingestion group compared to the TAG group. Differences were more pronounced for changes in chylomicron TAG and RLP-TAG levels.

Long-term studies conducted on the ad-libitum consumption of DAG oil in adults include a randomized, double blind, controlled, parallel trial, in which 312 adults were randomized into either a treatment (DAG oil, $n=155$ ) or placebo (TAG oil, $n=$ 157) product group (Koyama et al., 2003). The subjects were in overall good health with a BMI of $\geq 25 \mathrm{~kg} / \mathrm{m}^{2}$ and/or a fasting serum triglyceride level of $\geq 150 \mathrm{mg} / \mathrm{dl}$. They consumed DAG oil for one year without any dietary restrictions and maintained a constant level of physical activity. BMI $(p=0.002)$ and skinfold thickness $(p=0.028)$ decreased significantly in the DAG group compared to the TAG group.

In conclusion, the long-term consumption of DAG oil when it simply replaces conventional cooking oil may modestly but significantly reduce body weight and prevent weight gain as compared with TAG oil consumption, even at a similar calorie intake. Thus, DAG oil may be beneficial for maintaining a healthy body weight.

In addition to these parallel controlled studies, a two-year monadic study $(n=60) \quad$ (Otsuki et al., 2003) and a one-year monadic study $(n=114)$ (Katsuragi et al., 1999) have also been conducted. Similar efficacies were noted and the number of risk factors for subjects who initially had more than three categories of risk factors of metabolic syndrome were significantly decreased in the two-year study. No serious adverse effects with respect to hematology or serum chemistry were noted.

\section{Further applications of DAG}

We found significant beneficial effects of DAG over TAG oil by examining the effect of the difference in acylglycerol structure with the same fatty acid composition. $\omega-3$ polyunsaturated fatty acids in foods, such as EPA, DHA and ALA are of interest, as described in the previous section. We pursued the more potent beneficial effects of DAG by incorporating $\omega-3$ PUFA into the DAG structure. In this context, the effects of $\alpha$ linolenic acid-rich diacylglycerol (ALA-DAG) on body fat were investigated in obese model mice C57BL/6J. By incorporating a small amount $(1-4 \mathrm{wt} \%)$ of ALA-DAG in a diet high in both fat and sucrose (30 wt $\%$ and $13 \mathrm{wt} \%$, respectively), body weight gain and visceral fat gain were significantly reduced (Hase et al., 2001). These results, obtained by adding a small amount of ALA-DAG, indicate that the anti-obesity function is potentiated by incorporating ALA into the DAG structure, and also indicate the possible effectiveness of using ALA-DAG for the prevention and treatment of life-style related diseases.

In addition to obesity, hypercholesterolemia is another health concern since it has been shown to be associated with various life-style related diseases. Clinical investigations have revealed that the administration of phytosterols in human subjects reduces plasma total cholesterol and LDL cholesterol levels. Meguro et al. (2001) found that DAG was a better solvent for phytosterols than TAG. They investigated the difference in serum-cholesterol-lowering activities between phytosterols dissolved in DAG and those dispersed in TAG in humans. The administration at a level of $500 \mathrm{mg} /$ day of phytosterols dis- solved in DAG oil for two weeks significantly reduced total and LDL cholesterol levels from 5.57 to $5.31 \mathrm{mmol} / l$ (4.7\% reduction) and 3.69 to $3.39 \mathrm{mmol} / l(7.6 \%$ reduction) respectively, whereas the same amount of phytosterols dispersed in TAG oil had no significant effect (Meguro et al., 2001). Meguro et al. also showed that phytosterols in combination with DAG, as compared to TAG, prevents the development of atherosclerosis via a decrease in total serum cholesterol levels in rabbits (Megro et al., 2003). DAG oil containing phytosterols has been on the market in Japan since 2001 as a "Food for Specified Health Use" approved by the Ministry of Health, Labour and Welfare.

\section{Conclusion}

A cooking oil product containing $80 \%(\mathrm{w} / \mathrm{w})$ or more DAG has been used in Japan since 1999 as a "Food for Specified Health Use" approved by the Ministry of Health, Labour and Welfare. The approved claims are: (i) A lower elevation in postprandial TAG concentrations in the blood, and (ii) less likelihood of being stored as body fat.

In this communication, I have focused on the structural difference of acylglycerols instead of fatty acid composition in edible oils and discussed its effect on their nutritional characteristics influencing posoprandial lipemia and body fat accumulation. We can conclude that DAG oil has beneficial functions in human health as compared to conventional TAG oil.

The beneficial effects of DAG oil over the TAG oil are probably caused by its distinct metabolism after the absorption into mucosal cells, but not by its different bioavailability of the oils. Although studies of digestion, absorption and metabolic process are yet to be fully elucidated, the ingestion of DAG oil has been shown to be beneficial in reducing risk factors for lifestyle related diseases.

Regarding safety, DAG oil has been evaluated by the Japanese Ministry of Health and Welfare as a "Food for Specified Health Use" and has also been filed as GRAS (Generally Regarded As Safe) by the FDA in the United States. Clinical and mechanistic studies are still in progress to further confirm the efficacy, its mechanism and to increase the reliability of DAG oil for consumption under various conditions.

\section{References}

Abdel-Nabey, A.A., Shehata, Y., Ragab, M.H. and Rossell, J.B. (1992). Glycerides of cottonseed oils from Egyptian and other varieties. Riv. Ital. Sostanze Grasse, 69, 443-447.

Bray, G.A., Lovejoy, J.C., Most-Windhauser, M., Smith, S.R., Volaufova, J., Denkins, Y., de Jonge, L., Rood, J., Lefevre, M., Eldridge, A.L. and Peters, J.C. (2002). A 9-mo randomized clinical trial comparing fatsubstituted and fat-reduced diets in healthy obese men; the Ole Study. Am. J. Clin. Nutr., 76, 928-934.

Brown, J.M. and McIntosh, M.K. (2003). Conjugated linoleic acid in humans: regulation of adiposity and insulin sensitivity. J. Nutr:, 133, 3041-3046.

Cohen, J.C., Noakes, T.D. and Spinnler-Benade, A.J. (1988). Serum triglyceride responses to fatty meals: effects of meal fat content. Am. J. Clin. Nutr, 47, 825-827.

Cohn, J.S., McNamara, J.R., Cohn, S.D., Ordovas, J.M. and Schaefer, E.J. (1988). Postprandial plasma lipoprotein changes in human subjects of different ages. J. Lipid Res., 29, 469-479.

Cohn, J.S. (1998). Postprandial lipemia: emerging evidence for atherogenicity of remnant lipoproteins. Can. J. Cardiol., 14 suppl B, 18B-27B. Crossley, A., Freeman, I.P., Hudson, J.F. and Pierce, J.H. (1959). Acyl 
migration in diglycerides. J. Chem. Soc., 760-764.

D'alonzo, R.P., Kozarek, W.J. and Wade, R.L. (1982). Glyceride composition of processed fats and oils as determined by glass capillary gas chromatography. J. Am. Oil Chem. Soc., 59, 292-295.

Davidson, M.H., Hauptman, J., DiGirolamo, M., Foreyt, J.P., Halsted, C.H., Heber, D., Heimburger, D.C., Lucas, C.P., Robbins, D.C. Chung, J. and Heymsfield, S.B. (1999). Weight control and risk factor reduction in obese subjects treated for 2 years with orlistat: a randomized controlled trial. JAMA, 281, 235-242.

de Lorgeril, M. and Salen, P. (2003). Dietary prevention of coronary heart disease: focus on omega-6/omega-3 essential fatty acid balance. World Rev. Nutr: Diet, 92, 57-73.

Dubois, C., Beaumier, G., Juhel, C., Armand, M., Portugal, H., Pauli, A.M., Borel, P., Latge, C. and Lairon, D. (1998). Effects of graded amounts $(0-50 \mathrm{~g})$ of dietary fat on postprandial lipemia and lipoproteins in normolipidemic adults. Am. J. Clin. Nutr., 67, 31-38.

Eriksson, M., Angelin, B., Henriksson, P., Ericsson, S., Vitols, S. and Berglund, L. (1991). Metabolism of lipoprotein remnants in humans: studies during intestinal infusion of fat and cholesterol in subjects with varying expression of the low density lipoprotein receptor. Arterioscler: Thromb., 11, 827-837.

Gianturco, S.H. and Bradley, W.A. (1991). A cellular basis for the atherogenicity of triglyceride-rich lipoproteins. Atheroscler Rev., 22, 9-14.

Goldberg, I.J. (1996). Lipoprotein lipase and lipolysis: central roles in lipoprotein metabolism and atherogenesis. J. Lipid Res., 37, 693-707.

Hase, T., Mizuno, T., Onizawa, K., Kawasaki, K., Nakagiri, H., Komine, Y., Murase, T., Meguro, S., Tokimitsu, I., Shimasaki, H. and Itakura, H. (2001). Effects of $\alpha$-linolenic acid rich diacylglycerol on dietinduced obesity in mice. J. Oleo Sci., 50, 701-710.

Ide, T., Kobayashi, H., Ashakumary, L., Rouyer, I.A., Takahashi, Y., Aoyama, T., Hashimoto, T. and Mizugaki, M. (2000). Comparative effects of perilla and fish oils on the activity and gene expression of fatty acid oxidation enzymes in rat liver. Biochim. Biophys. Acta, $\mathbf{1 4 8 5}$, $23-35$.

Ikemoto, S., Takahashi, M., Tsunoda, N., Maruyama, K., Itakura, H. and Ezaki, O. (1996). High-fat diet-induced hyperglycemia and obesity in mice: differential effects of dietary oils. Metabolism, 45, 1539-1546.

Jeppesen, J., Chen, Y.D., Zhou, M.Y., Wang, T. and Reaven, G.M. (1995). Effect of variations in oral fat and carbohydrate load on postprandial lipemia. Am. J. Clin. Nutr, 62, 1201-1205.

Jump, D.B. and Clarke, S.D. (1999). Regulation of gene expression by dietary fat. Annu. Rev. Nutr., 19, 63-90.

Kabir, Y. and Ide, T. (1996). Activity of hepatic fatty acid oxidation enzymes in rats fed alpha-linolenic acid. Biochim. Biophys. Acta, 1304, 105-119.

Kasai, M., Nosaka, N., Maki, H., Negishi, S., Aoyama, T., Nakamura, M., Suzuki, Y., Tsuji, H., Uto, H., Okazaki, M. and Kondo, K. (2003). Effect of dietary medium- and long-chain triacylglycerols (MLCT) on accumulation of body fat in healthy humans. Asia Pac. J. Clin. Nutr., $12,151-60$

Kodali, D.R., Tercyak, A., Fahey, D.A. and Small, D.M. (1990). Acyl migration in 1,2-dipalmitoyl-sn-glycerol. Chem. Phys. Lipids., 52 $163-70$.

Kondo, H., Hase, T., Murase, T. and Tokimitsu, I. (2003). Digestion and assimilation features of dietary DAG in the rat small intestine. Lipids, 38, 25-30.

Katsuragi, Y., Toi, T., and Yasukawa, T. (1999). Effects of Dietary Diacylglycerols on Obesity and Hyperlipidemia, J. Jpn. Human Dry Dock. 14, 258-262.

Koyama, W., Kawashima, H., Wakagi, Y., Mori, K., Takase, H., Yamaguchi, T. (2003). Long-term effects of diacylglycerol used ad libitum as cooking oil in home. 24th Annual Meeting of Japan Society for the Study of Obesity, Chiba, Japan, Nov. 13-14.

Larsen, T.M., Toubro, S. and Astrup, A. (2003). Efficacy and safety of dietary supplements containing CLA for the treatment of obesity: evidence from animal and human studies. J. Lipid Res., 44, 2234-41.

Lehner, R., Kuksis, A. and Itabashi, Y. (1993). Stereospecificity of monoacylglycerol and diacylglycerol acyltransferases from rat intestine as determined by chiral phase high-performance liquid chromatography. Lipids, 28, 29-34.

Levy, A.S. and Heaton, A.W. (1993). Weight control practices of US adults trying to lose weight. Ann. Intern. Med., 119, 661-666.

Maki, K.C., Davidson, M.H., Tsushima, R., Matsuo, N., Tokimitsu, I., Umporowicz, D.M., Dicklin, M.R., Foster, G.S., Ingram, K.A., Anderson, B.D., Frost, S.D. and Bell, M. (2002). Consumption of diacylglycerol oil as part of a reduced-energy diet enhances loss of body weight and fat in comparison with consumption of a triacylglycerol control oil. Am. J. Clin. Nutr., 76, 1230-1236.

Matsuzawa, Y., Nakamura, T., Shimomura, I. and Kotani, K. (1995). Visceral fat accumulation and cardiovascular disease. Obes. Res., 3 , 645S-647S.

Meguro, S., Higashi, Hase, T., Honda, Y., Otsuka, A., Tokimitsu, I., and Itakura, H. (2001) Solubilization of phytosterols in diacylglycerol versus triacylglycerol improves the serum cholesterol-lowering effect. Eur. J. Clin. Nutr: 55, 513-517.

Meguro, S., Hase, T., Otsuka, A., Tokimitsu, I. and Itakura, H. (2003) Effect of phytosterols in dietary diacylglycerol on atherosclerosis in cholesterol-fed rabbits. Nutrition, 19, 670-675.

Mokdad, A.H., Ford, E.S., Bowman, B.A., Dietz, W.H., Vinicor, F., Bales, V.S. and Marks, J.S. (2003). Prevalence of obesity, diabetes, and obesity-related health risk factors, 2001. JAMA, 289, 76-79.

Murase, T., Mizuno, T., Omachi, T., Onizawa, K., Komine, Y., Kondo, H., Hase, T. and Tokimitsu, I. (2001). Dietary diacylglycerol suppresses high fat and high sucrose diet-induced body fat accumulation in C57BL/6J mice. J. Lipid Res., 42, 372-378.

Murase, T., Aoki, M., Wakisaka, T., Hase, T. and Tokimitsu, I. (2002). Anti-obesity effect of dietary diacylglycerol in C57BL/6J mice: dietary diacylglycerol stimulates intestinal lipid metabolism. J. Lipid Res., 43, $1312-1319$.

Murata, M., Ide, T. and Hara, K. (1997). Reciprocal responses to dietary diacylglycerol of hepatic enzymes of fatty acid synthesis and oxidation in the rat. Br. J. Nutr., 77, 107-121.

Murata, M., Hara, K. and Ide, T. (1994). Alteration by diacylglycerols of the transport and fatty acid composition of lymph chylomicrons in rats. Biosci. Biotechnol. Biochem., 58, 1416-1419.

Nagao, T., Watanabe, H., Goto, N., Onizawa, K., Taguchi, H., Matsuo, N., Yasukawa, T., Tsushima, R., Shimasaki, H. and Itakura, H. (2000). Dietary diacylglycerol suppresses accumulation of body fat compared to triacylglycerol in men in a double-blind controlled trial. J. Nutr., 130, 792-797.

National Institute of Health, National Heart, Lung, and Blood Institute, Obesity Education Initiative. (1998). "Clinical Guidelines on the Identification, Evaluation, and Treatment of Overweight and Obesity in Adults." National Institute of Health, Bethesda, Md.

Otsuki, K., Mori, K., Onodera, Y. (2003) Final report from two-year intervention using edible oil rich in diacylglycerol. 44th Annual Meeting of the Japanese Society of Human Dry Dock, Kyoto, Japan, Aug. $27-29$.

Patsch, J.R, Miesenbock, G., Hopferwieser, T., Muhlberger, V., Knapp, E., Dunn, J.K., Gotto, A.M. Jr. and Patsch, W. (1992). Relation of triglyceride metabolism and coronary artery disease: studies in the postprandial state. Arterioscler: Thromb., 12, 1336-1345.

Patsch, J.R. (1987). Postprandial lipaemia. Baillieres Clin. Endocrinol. Metab., 1, 551-580.

Rimm, E.B., Stampfer M.J., Giovannucci E., Ascherio A., Spiegelman D., Colditz G.A. and Willett, W.C. (1995). Body size and fat distribution as predictors of coronary heart disease among middle-aged and older US men. Am. J. Epidemiol., 141, 1117-1127.

Sinclair, A.J., Attar-Bashi, N.M. and Li, D. (2002). What is the role of alpha-linolenic acid for mammals?. Lipids, 37, 1113-1123.

St-Onge, M.-P. and Jones, P.J.H. (2002). Physiological effects of medium-chain triglycerides: potential agents in the prevention of obesity. J. Nutr., 132, 329-332.

Stubbs, R.J. (2001). The effect of ingesting olestra-based foods on feeding behavior and energy balance in humans. Crit. Rev. Food Sci. Nutr., 41, 363-386.

Tada, N., Watanabe, H., Matsuo, N., Tokimitsu, I. and Okazaki, M. (2001). Dynamics of postprandial remnant-like lipoprotein particles in serum after loading of diacylglycerols. Clin. Chim. Acta, 311, 109117

Taguchi, H., Nagao, T., Watanabe, H., Onizawa, K., Matsuo, N., Tokimitsu, I. and Itakura, H. (2001). Energy value and digestibility of dietary 
oil containing mainly 1,3-diacylglycerol are similar to those of triacylglycerol. Lipids, 36, 379-382.

Taguchi, H., Watanabe, H., Onizawa, K., Nagao, T., Gotoh, N. Yasukawa, T., Tsushima, R., Shimasaki, H. and Itakura, H. (2000). Double-blind controlled study on the effects of dietary diacylglycerol on postprandial serum and chylomicron triacylglycerol responses in healthy humans. J. Am. Coll. Nutr., 19, 789-796.

Takase, H., Takei, A., Toi, T., Takahashi, H., Takeda, Y., Moriwaki, J. Katsuragi, Y., Tada, N. and Itakura, H. (2003). Nutritional studies of single-dosed or prolonged mayonnaise-type diacylglycerol supplementation in humans. Presented at 57th Annual Meeting of the Japanese Society of Nutrition and Food Science, Fukuoka, May 17-19.

Tomonobu, K. Hase, T. and Tokimitsu, I. (2003). Subsequent blood lipid variance in subjects consuming diacylglycerol meal. Presented at 25th Annual Meeting of Japan Society of Clinical Nutrition, Yokohama, Oct. 3-5.

Tsuji, H., Kasai, M. Takeuchi, H. Nakamura, M. Okazaki, M. and Kondo, K. (2001). Dietary medium-chain triacylglycerols suppress accumulation of body fat in a double-blind, controlled trial in healthy men and women. J. Nutr., 131, 2853-2859.

Vanschoonbeek, K., de Maat, M.P. and Heemskerk, J.W. (2003). Fish oil consumption and reduction of arterial disease. J. Nutr., 133, 657-660.

Watanabe, T., Shimizu, M., Sugiura, M., Sato, M., Kohori, J., Yamada, N. and Nakanishi, K. (2003). Optimization of reaction conditions for the production of DAG using immobilized 1,3-regiospecific lipase lipozyme RM IM. J. Am. Oil Chem. Soc., 80, 1201-1207.

Watanabe, H., Onizawa, K., Taguchi, H., Kobori, M., Chiba, H., Naito,
S., Matsuo, N., Yasukawa, T., Hattori, M. and Shimasaki, H. (1997). Nutritional characterization of diacylglycerols in rats. J. Jpn. Oil. Chem. Soc., 46, 301-307 (in Japanese).

Weisinger, H.S., Armitage, J.A., Sinclair, A.J., Vingrys, A.J., Burns, P.L. and Weisinger, R.S. (2001). Perinatal omega-3 fatty acid deficiency affects blood pressure later in life. Nat. Med., 7, 258-259.

Wirth, A. and Krause, J. (2001). Long-term weight loss with sibutramine: a randomized controlled trial. JAMA, 286, 1331-1339.

Wylie-Rosett, J. (2002). Fat substitutes and health: an advisory from the Nutrition Committee of the American Heart Association. Circulation, 105, 2800-2804.

Yamamoto, K., Asakawa, H., Tokunaga, K., Watanabe, H., Matsuo, N., Tokimitsu, I. and Yagi, N. (2001). Long-term ingestion of dietary diacylglycerol lowers serum triacylglycerol in type II diabetic patients with hypertriglyceridemia. J. Nutr., 131, 3204-3207.

Yanagita, T. and Ikeda, I. (2003). Digestion and absorption of diacylglycerol. In "Essential fatty acids and eicosanoids: invited papers from the Fifth International Congress," ed. by Huang, Y-S., Lin, S-J. and Huang, Po-C. AOCS Press, Champaign, IL, pp. 316-320.

Yasunaga, K., Seo, Y., Katsuragi, Y., Oriuchi, N., Ootake, H., Endo, K. and Yasukawa, T. (2000). Gastric emptying rate of dietary diacylglycerol. Presented at 54th Annual Meeting of the Japanese Society of Nutrition and Food Science. Matsuyama, May12-14.

Zilversmit, D.B. (1979). Atherogenesis: a postprandial phenomenon. Circulation, 60, 473-485.

Zimmet, P., Alberti, K.G. and Shaw, J. (2001). Global and societal implications of the diabetes epidemic. Nature, 414, 782-787. 